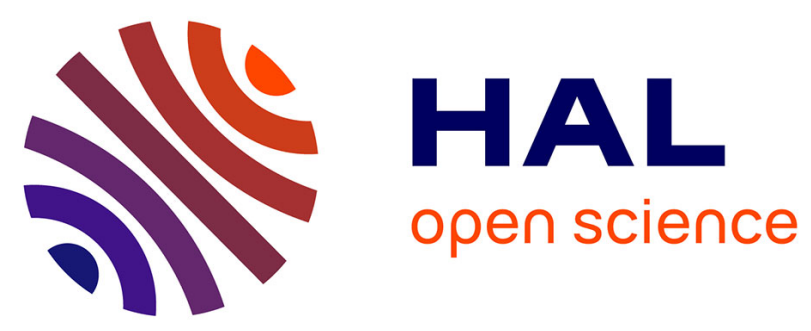

\title{
STUDY OF SOME OPTICAL AND ELECTRICAL PROPERTIES OF HEAVILY DOPED SILICON LAYERS
}

\author{
A. Slaoui, E. Fogarassy, J. Muller, P. Siffert
}

\section{- To cite this version:}

A. Slaoui, E. Fogarassy, J. Muller, P. Siffert. STUDY OF SOME OPTICAL AND ELECTRICAL PROPERTIES OF HEAVILY DOPED SILICON LAYERS. Laser-Solid Interactions and Transient Thermal Processing of Materials, 1983, Strasbourg, France. pp.C5-65-C5-71, 10.1051/jphyscol:1983509 . jpa-00223089

\section{HAL Id: jpa-00223089 https://hal.science/jpa-00223089}

Submitted on 1 Jan 1983

HAL is a multi-disciplinary open access archive for the deposit and dissemination of scientific research documents, whether they are published or not. The documents may come from teaching and research institutions in France or abroad, or from public or private research centers.
L'archive ouverte pluridisciplinaire HAL, est destinée au dépôt et à la diffusion de documents scientifiques de niveau recherche, publiés ou non, émanant des établissements d'enseignement et de recherche français ou étrangers, des laboratoires publics ou privés. 
JOURNAL DE PHYSIQUE

Colloque $C 5$, supplément au $n^{\circ} 10$, Tome 44, octobre 1983

page $C 5-65$

STUDY OF SOME OPTICAL AND ELECTRICAL PROPERTIES OF HEAVILY DOPED SILICON LAYERS

\author{
A. Slaoui, E. Fogarassy, J.C. Muller and P. Siffert \\ Centre de Recherches Nucléaires, Laboratoire PHASE', 67037 Strasbourg Cedex, \\ Erance
}

Résumé - On étudie certaines propriétés optiques de couches de silicium dopées au-delà de la solubilité maximale à l'équilibre par un procédê d'implantation suivi d'une fusion laser.

Des plaquettes de silicium de type $P$ sont implantées à des doses allant jusqu'à $10^{17} \mathrm{~cm}^{-3}$ par des ions arsenic ( $80 \mathrm{KeV}$ ), puis les dopants sont incorporés au réseau par une fusion laser induite par un laser pulsé au YAG à des énergies allant jusqu'à $2,5 \mathrm{~J} / \mathrm{cm}^{2}$ pour des durées d'impulsions de 25 et 100 ns, respectivement.

La rēflectivité des couches entre 250 et $500 \mathrm{~nm}$ ainsi que des mesures ellipsométriques ont été effectuées en fonction des conditions expérimentales. Aux fortes doses les défauts jouent un rôle non négligeable sur ces propriêtēs optiques.

Abstract - It is well known that the solubility of most dopants can be noticeably increased in silicon by pulsed laser annealing of the implanted layers. Here, we have investigated the evolution of some optical and electrical properties of such heavily doped layers as a function of implanted dose, trying to separate effects due to the high doping from those resulting from defects or precipitates.

p-type silicon wafers have been implanted with $80 \mathrm{KeV}$ arsenic ions at doses of up to $10^{17} \mathrm{~cm}^{-2}$ and annealed by a pulsed ruby and YAG laser, giving pulses of 20 and 100 ns duration, respectively and depositing energies up to $2.5{\mathrm{~J} . \mathrm{cm}^{-2}}^{-2}$.

U.V. and visible light (250 and $500 \mathrm{~nm}$ ) reflectance, as well as ellipsometry $(632.8 \mathrm{~nm})$ measurements have been performed as well as dark $\mathrm{I}-\mathrm{V}$ and $\mathrm{C}-\mathrm{V}$ characteristics.

These investigations indicate that by increasing the implanted dose, the doping level first increases until near surface defects and precipitates modify the optical as well as the electrical properties of the heavily doped layers. The generation of these defects has been followed by RBS in random and channelling conditions.

\title{
INTRODUCTION
}

In the fabrication of sophisticated devices such as the bipolar transistor used in modern silicon integrated circuits, integrated injection logic ( $I^{2} L$ ) and solar cells, the use of high - dose ion - implanted laser - annealed single - crystal silicon allowed (1) formation of both highly doped shallow $\mathrm{N}^{+}$and $\mathrm{P}^{+}$layers. 
A high - power laser irradiation can anneal the ion - implanted damage region in single - crystal semi-conductors. Rapid surface melting and subsequent liquid phasi epitaxial regrowth in nanosecond pulse annealing make it possible to dope silicon with electrically active impurities well above the thermal equilibrium solid solubility 7 imit (2), and to completely anneal implanted regions without any macroscopically extented defects, such as dislocations, stacking facets or precipitations (3). Three techniques are used to analyze electrical and structural properties of laser - annealed damage : electron microscopy, He ${ }^{+}$backscattering (3) and optica spectroscopy $(4,5)$ mainly in the UV and visible range. Indeed, for photon energies smaller than Eo, that is for edge absorption, the semi-conductor is more or less transparent (free absorption); for energies larger than Eo, it is opaque (band to band absorption). The former gives information about various lattice imperfection (e.g. impurities, defects, phonons, etc .... The latter is mainty related to the band structure and contributes essentially to a detailed understanding of the electronic structure of the semi-conductor (6). Pankove (7) has studied extensively the optical properties of heavily doped germanium and has shown the modification in band structure and its consequence on electrical properties of $P-N$ junctions.

In this paper, we attempt to characterize heavily doped silicon layers by UV and visible reflectivity experiments and by electrical measurements for very large doping concentrations.

\section{EXPERIMENTS}

Several P-type (100) Si wafers, of $1-5 \Omega . \mathrm{cm}$ resistivities, were implanted with $\mathrm{As}^{+}(80 \mathrm{KeV})$ ions. The doses ranged between $10^{15}$ and $10^{17} \mathrm{~cm}^{-2}$. This operation was followed by $Q$ - switched pulse YAG or ruby laser treatment. The parameters of the lasers are respectively : $\lambda=0.532$ and $0.690 \mathrm{~nm}$, duration time $=100$ and $20 \mathrm{~ns}$, pulse energy $=2.5$ and $1.4 \mathrm{~J} / \mathrm{cm}^{2}$. After 7 aser annealing, almost all implanted impurities were located in substitutional positions, as confirmed by RBS. The maximum carrier concentrations in the crystals were between $8 \times 20^{20}$ and $4.3 \times 10^{21} \mathrm{~cm}^{-3}$ (Fig. 1, Table 1) for an implanted dose of $10^{16}$ to $5 \times 10^{16} \mathrm{~cm}^{-2}$.

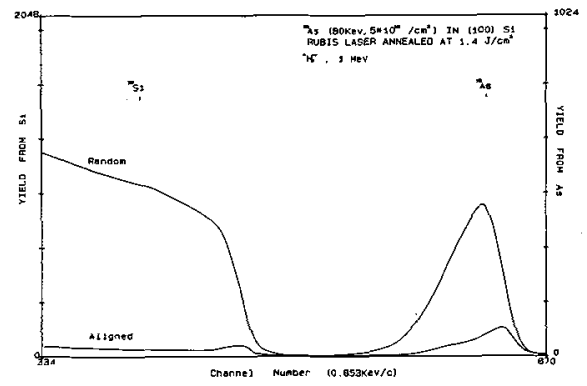

Fig. 1 - RBS spectra for both $\mathrm{Si}$ and As after laser annealing. The maximum carrier concentration is

$$
4.3 * 10^{21} \mathrm{~cm}^{-3}
$$

\begin{tabular}{|c|c|c|}
\hline $\begin{array}{c}\text { Imp1. Dose } \\
\text { (*1E16/cm2) }\end{array}$ & $\begin{array}{c}\text { Sheet carrier } \\
\text { conc. } \\
\text { (*1E16/cm2) }\end{array}$ & $\begin{array}{c}\text { Max. conc. } \\
\text { (*1E21/cm3) }\end{array}$ \\
\hline 1 & 1 & 0.82 \\
\hline 3 & 2.97 & 2.73 \\
\hline 5 & 4.85 & 4.35 \\
\hline
\end{tabular}

Table 1 - The samples are annealed by Taser YAG $(\lambda=0.53 \mu \mathrm{m})$ at energy density $2.5 \mathrm{~J} / \mathrm{cm}^{2}$. 
The optical reflectivity spectra were performed by using a Beckmann double beam spectrophotometer over the range $2500-5000 \AA$. An evaporated aluminium mirror, whose reflectance was assumed to be $100 \%$, provided the reference spectrum. The ellipsometry measurements at $\lambda=6328 \mathrm{~A}$ (He - Ne) were performed on VAG annealed samples at doses $10^{16}$ to $5 \times 10^{16} \mathrm{~cm}^{-2}$. Just prior to both types of measurements above the samples were cleaned by fluoridric solution to remove any oxide layer. For electrical measurements, the front contact was realized with Ag evaporation on small nesas and back contact was performed with evaporated gold. The sheet-resistance data was measured with a four - point probe.

\section{RESULTS AND DISCUSSION}

\section{1) OPTICAL CHARACTERISTICS}

The reflectivity spectra of substrate crystal and doped silicon are shown in Fig. 2. Two peaks at $3650 \AA$ and $2750 \AA$ are observed, and denoted $E_{1}, E_{2}$ respectively. The $E_{1}$ (3.4 ev) peak, initially attributed to an interband transition $\Gamma_{25}^{\prime \prime}-\Gamma_{15}$, has been revealed (8) to be a mixture of $\Gamma_{25}^{1}-\Gamma_{15}$, $L_{3}^{\prime}-L_{1}$ and $\Gamma_{25}^{\prime}-\Gamma_{2}^{\prime}$ transitions $\left(\mathrm{Fig}^{1} 3\right)$. As to the $E_{2}$ peak $(4.5 \mathrm{ev})$, it is due to the accidental degeneracy of an $M_{1}$ edge due to the $x_{4}-x_{1}$ transition and an $M_{2}$ edge due to the $\Sigma_{4}-\Sigma_{1}$ transition (8) (Fig. 3). Both peaks were pratically unaffected when the doping dose was less than $10^{16} \mathrm{~cm}^{-2}$ (Fig. 3). However, the peaks were appreciabiy degraded as the doping concentration increased. At $10^{17} \mathrm{As}^{+} / \mathrm{cm}^{2}$ the $E_{2}$ peak nearly desappears. We introduce the reflectivity change $\Delta R$, defined as the deviation from the crystalline substrate reflectivity at $2750 \AA$ to better distinguish the change with doping. As previously implied, $R$ starts to increase when dose exceeds $10^{16} \mathrm{~cm}^{-2}$ (Fig. 4). This kind of behaviour has been al ready reported for $P$ and As implanted and ruby laser annealed silicon (9). As has been shown (9), the cause of the degradation of the $\mathrm{E}_{2}$ peak is neither due to free carriers nor to stress caused by impurity atoms, but rather to supersaturated solid solutions of arsenic in the silicon lattice. It is clear that this reflectivity reduction is related to the change in band structure due to the high doping.

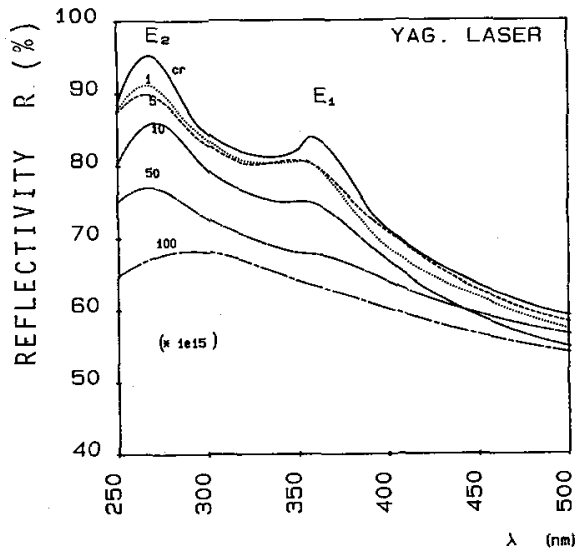

Fig. 2 - Optical reflectivity spectra for crystal (Cr) and ion-implanted laser-annealed $\mathrm{Si}$. The dose ranges between 1 and $100 \times 10^{15}$ $\mathrm{As}^{+} / \mathrm{cm}^{2}$.

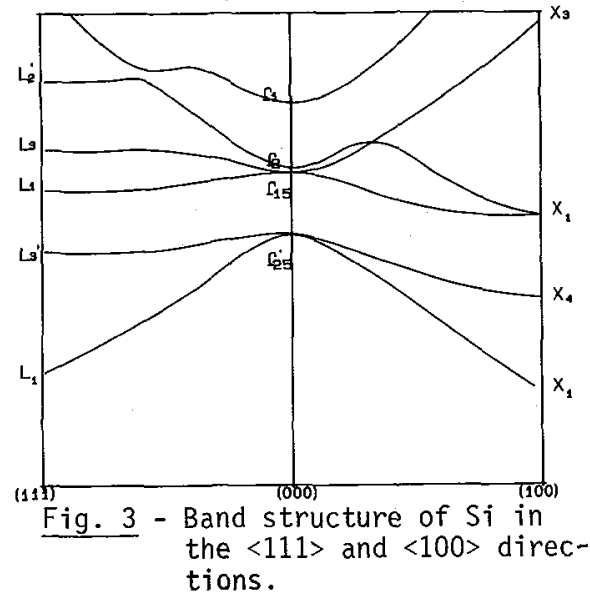




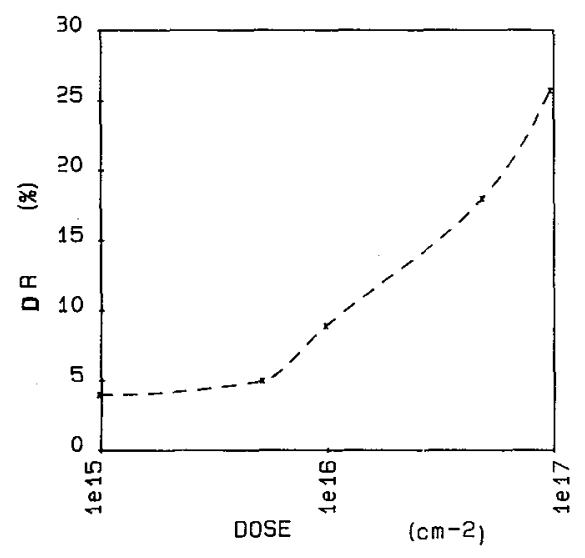

Fig. 4 - The reflectivity change $\Delta R$ (deviation from the crystal Si reflectivity at $2750 \mathrm{~A}$ ) versus implanted dose.

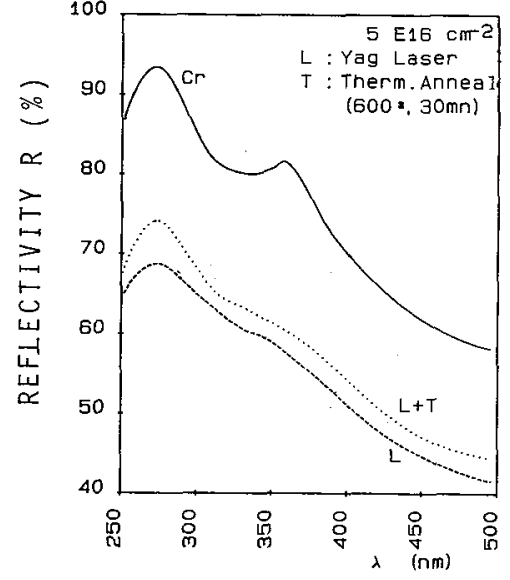

Fig. 5 - Optical reflectivity spectra for crystalline $(-)$ and doped $\left(4.5 * 10^{21} \mathrm{~cm}^{-3}\right)$ Si. L designates laser annealing $\left(2.5 \mathrm{~J} / \mathrm{cm}^{2}\right)$ and $T$ therma 7 annealing $\left(600^{\circ} \mathrm{C}\right.$, $20 \mathrm{mn}$ )

In Fig. 5 shows reflectivity spectra for $5 \times 10^{16} / \mathrm{cm}^{2}$ doping dose before and after thermal annealing $\left(600^{\circ} \mathrm{C}, 20 \mathrm{mn}\right)$. After laser annealing, the highly substitutional arsenic concentration in silicon is metastable. Thermal annealing increases the fraction of interstitial atoms and consequently the number of active atoms decreases, as seen by sheet resistivity measurements. There results, as observed in Fig. 5 , the increase of the $E_{2}$ peak. We can conclude that the reflectivity reduction is mainly due to high doping level. Similar behaviour is observed for ruby laser annealed samples.

Several reports in the 7 iterature $(10,11)$ investigated the effects of Taser annealing on ion implanted silicon layers by using ellipsometry which is a fast and non-destructive method to characterize crystal damage. From ellipsometric measurements, is is possible to calculate refractive and extinction indices and absorption coefficients. Changes in optical constants can be attributed to transformation of the $\mathrm{S} i$ band structure after implantation and annealing.

Fig. 6 shows the refractive index and absorption coefficient as a function of implanted dose. The former decreases with increasing dose and saturation at $4 \times 10^{16} \mathrm{~cm}^{-2}$, but the second rises to value nearly on order of magnitude higher than the one for pure silicon. Ostaja et al. (5) suggest that the very highly doped layers are responsible for this increase of the absorption coefficient, giving low diffusion lenghts.

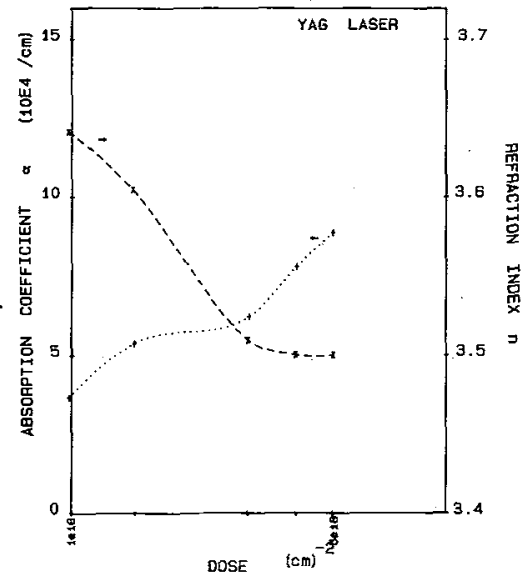

Fig. 6 - Absorption coefficient and refraction index $\mathrm{A}_{S}{ }^{+}$ implanted and YAG laser annealed silicon versus implanted dose. 


\section{2) ELECTRICAL CHARACTERISTICS}

The electrical activity of the implanted arsenic atoms was proved by sheet resistance measurements as shown in Fig. 7. We observe, for $Y A G$ and ruby laser treatments, a decrease of $R$ as the dose increases from $10^{15}$ to $5 \times 10^{16} \mathrm{~cm}^{-2}$, followed by an increase for doses between $5 \times 10^{16}$ and $10^{17} \mathrm{~cm}^{-2}$. The possibility was considered that the laser energy density was not sufficient to anneal and activate al1 dopants at $10^{17} \mathrm{As}^{+} / \mathrm{cm}^{2}$ and that precipitation has taken place due to the As solubility $1 \mathrm{i}$ mit $\left(6 \times 10^{21} \mathrm{~cm}^{-3}\right)(12)$ after annealing. On the same figure, two other curves are plotted : the first (solid line) is the Smith et al. curve (13) for deviation $\sigma_{S}=250 \AA$ which has been extrapolated to a dose higher than $10^{16} \mathrm{~cm}^{-2}$. The second curve was derived from the equation $R=\left(q N_{S} \mu\right)^{-1}$ where $N_{s}$ corresponds to the total number of implanted ions per unit surface are, and $\mu$ is the electron mobility given by $\mathrm{Hill}_{1}$ (14) for carrier concentration $\mathrm{C}$ between $10^{20}$ and $10^{22} \mathrm{~cm}^{-3}$. $\mu=7.5 \times 10^{11} \mathrm{C}^{-1 / 2} ; \mathrm{N}_{\mathrm{S}}$ and $\mathrm{C}$ were determined by RBS for each dose. Calculated vaTues were found to be in good agreement. For doses in excess of $5 \times 10^{15} \mathrm{~cm}^{-2}$, $R$ ( $Y A G$ ) is lower than $R$ (ruby) because the junction is deeper for the YAG laser irradiation. This is due to the difference in the pulse duration of YAG $(\tau=100 \mathrm{~ns}$ ) and ruby $(\tau=20 \mathrm{~ns})$ lasers in which the longer pulse indices a thicker melting zone. The values found are much low $(\simeq 10 / \mathrm{SQ})$, implying a very good electrical activation of the dopant.
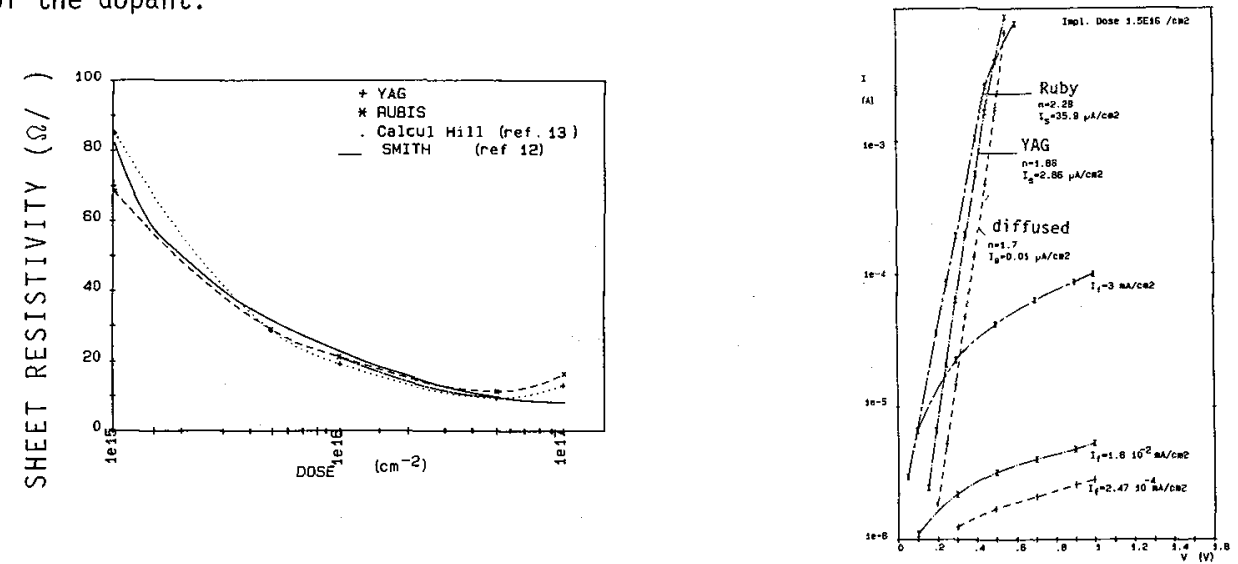

Fig. 7 - Sheet resistivity versus implanted dose. The pulse energy for YAG and ruby layers are 2.5 and 1.4 $\mathrm{J} / \mathrm{cm}^{2}$ respectively. The values calculated $\leftarrow .-$ ) gives good agreement with experiment (... and -.- ).

Fig. 8 - Dark forward and reverse $I-V$ characteristics $I=I_{s}\left(\frac{q V}{n k T}-1\right)$

where $I_{s}$ is the saturation current, $n$ the quality factor If is the reverse Teakage current.

We report in Fjg. 8, the dark forward and reverse current-voltage characteristics of the laser annealed junctions and of the thermal diffused diode. The forward current recombination factor $n_{r}$ as defined by $J=J o r\left|\exp \left(q V / n_{r} k T\right)-1\right|$ was calculated over the range 0 to 0.35 volts. Contrary to diffused junctions, the devices annealed by YAG or ruby lasers exhibited recombination factor in the range 1.6 to 4.2 implying the existence of a larger space charge region and surface concentration of defects that act as generation - recombination centers (Table II). These high values of $n_{r}(>2)$ are not predicted by the Sah - Noyce and Shockley $(S-N-S)$ theo- 
ry (15), but could be due in part to shunt resistance effects and in part to modifications in the S - N - S theory which account for non-uniformities in the distribution of recombination centers (16). The high level of doping makes for diffusion $I_{d}$ and recombination $I_{r}$ saturation currents that are more than one order of magnitude higher than those of diffused diodes, suggesting a change in diffusion constant $D$, diffusion lenght $L$ and intrinsic concentration $n_{i}$ composing the saturation current. For heavily doped layers, $n_{i}$ is remplaced by an effective intrinsic concentration $n_{i e}$ such that $\quad n_{i e}=n_{j} \exp \left(-\frac{\Delta E g}{k T}\right)$ where $\Delta E g$ is the shrinkage band gap (17). Another electrical characteristic is the leakage, or reverse, current, which we take as $V_{a}=-1$ volt. The reverse leakage current, $I_{f}$, is due to three mechanisms : carrier diffusion, generation of carriers within the depletion regions, and generation of carriers due to the introduction of recombination centers at the surface of the $p-n$ junctions. This third mechanism is prevalent and largely exceeds the importance of the other two (18). As for the recombination quality factor $n_{r}$, the increase of the reverse current in implanted and laser annealed junctions can be due to surface, and space charge induced defects. Since we have observed similar behaviour for laser annealed diffused junctions (19), we suggest that the properties of the surface after laser treatment (high doping leve1, dangling-bands, high absorption coefficient, recombination velocity, etc ...) are mainly responsible of the high measured reverse current.

\begin{tabular}{|c|c|c|c|c|c|c|}
\hline $\begin{array}{l}\text { DOSEE } \\
\text { Icm-a }\end{array}$ & 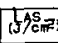 & $n_{0}$ & 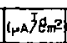 & $n_{r}$ & 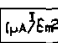 & 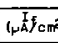 \\
\hline & $Y$ & 1.63 & 2.23 & 1.03 & 2.23 & 10 \\
\hline & A & 1.82 & 14.88 & 1.82 & 14.89 & 413 \\
\hline \multirow[t]{2}{*}{$\stackrel{\nabla}{*}$} & $r$ & 1.86 & .85 & 1.86 & 2.86 & 16 \\
\hline & A & 2.29 & 95. 95 & 2.29 & 35.96 & 383 \\
\hline \multirow{2}{*}{ 䍖 } & y & 1.62 & .63 & 1.62 & 0.63 & 6 \\
\hline & B & 1.6 & 0.5 & 3.78 & 40 & 1.5e \\
\hline \multirow{2}{*}{ 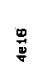 } & $Y$ & 2.5 & 0.57 & 2.51 & 0.57 & 3 \\
\hline & A & 1.5 & 0.32 & 4.2 & e6.2 & $2.5 \mathrm{e}$ \\
\hline \multirow[b]{2}{*}{ 葛 } & $Y$ & 1.7 & 0.318 & 1.7 & 0.318 & 10 \\
\hline & A & 1.7 & 2.38 & 3.2 & 55 & $3.5 \mathrm{e}$ \\
\hline OLFF & THEPM & 1.7 & 0.01 & 1.7 & 0.01 & 0.2 \\
\hline
\end{tabular}

Table II - We assumes

$$
\begin{aligned}
& I=I_{O D}\left(\exp \frac{q V}{n_{D} k T}-1\right) \\
& +I_{O R}\left(\exp \frac{q}{n_{r} k T}-1\right) \\
& \text { where } I_{O D} \text { and } I_{O R} \text { are the } \\
& \text { diffusion and recombination } \\
& \text { saturation currents respecti- } \\
& \text { vely. }
\end{aligned}
$$

\begin{tabular}{|c|c|c|c|c|c|}
\hline $\begin{array}{l}\text { DOSE } \\
\text { 1e16cm }\end{array}$ & 1 & 1.5 & 3 & 4 & 5 \\
\hline $\begin{array}{c}\phi(Y) \\
(V)\end{array}$ & 0.635 & 0.48 & 0.506 & 0.526 & 0.549 \\
\hline $\begin{array}{c}\phi(\mathrm{R}) \\
(V)\end{array}$ & 0.508 & 0.643 & 0.518 & 0.482 & 0.508 \\
\hline
\end{tabular}

Table III - $\phi(Y)$ and $\phi$ designate diffusion potential for $Y A G$ and ruby annealed layers respectively. $\phi$ (diffus) is $=$ $0.93 \mathrm{~V}$.

Another electrical characteristic of the $p-n$ junctions is the diffusion potential which is a function of the impurity doping concentration and temperature, and is a result of the dipole charge layer at the junction. The magnitude of this charge layer is a function of the junction voltage and we define a depletion layer capacitance by

$$
c d=\left|\frac{d Q}{d V}\right|=K(\phi-V)^{-1 / n}
$$


where $K$ is a constant depending upon the doping concentration on the $p$ and $n$ sides of the junction, and $n$ is a constant normally lying between 2 and 3 , and is a measure of the doping profile. Here, we found $n=3$ implying a linearly graded junction. From these measurements, we deduce the diffusion potentiale $\phi$ presented in Table II. The $\phi$ values of implanted laser annealed junctions are very much lower than those of diffused diodes $(0.9 \mathrm{vol} t)$. This difference suggest the possibility of compensating defects in the junction region (20). As the diffusion potential is directly related to the energy band gap of the semi-conductor, and the $\phi$ are low, these results could indicate a shrinkage of the energy gap (7) due to the high doping level.

\section{CONCLUSION}

We have studied the electrical and optical characteristics of ion implanted laser annealed silicon. In particular, the decrease of the reflectivity and the increase of the absorption coefficient can be related to the degree of supersaturation of the solid solution which results from the very high doping level. There results degraded electrical characteristics (high recombination quality factor, high saturation and reverse currents) which could limit the performance of the devices.

\section{REFERENCES}

1. SHTYRKOV G.I., KHIBULLIN I.B., GALYATUDINOV M.F. and BAYAZITOV R.M. Sov. Phys. Semicond. 9 (1975) 1309.

2. LEITOLA A, and GIBBONS J.F.. Appl. Phys, Letters 35 (1979) 532.

3. NATSUAKI N., TAMURA M. and TOKUYAMAT T... J. AppT. Phys. 51 (1980) 3373.

4. MCGILL T.C., KURTIN S.L. and SHIFRIN G.A.. J. AppT. Phys. $\frac{14}{14}$ (1970) 246.

5. OSTOJA P., SOLMI S., ZANI A.. J. App1. Phys. 52 (1981) 6208.

6. TAUC J.C.. "Progress in Semiconductors" Vo1. 9 (Gibson and Burgess eds, Temple books, Ltd London, 1965) p. 88.

7. PANKOVE J.I.. Ibid, p. 48.

8. GREENAWAY D.L. and HARBEKE G.. "Optical properties and band structure of semiconductors" (ed. by PAMPLIN B.R., Pergamon Press, 1968).

9. MOTOOKA T., MIYAO M. and TOKUYAMA T.. J. Electrochem. SOC. Montreal (1982)

10. WATANABE K., MOTOOKA T., HSHIMOTO N. and TOKUYANA T.. Appl. Phys. Letters 36 (1980) 451.

11. NAKAMURA K., KAMOSHIDA M., VEHARA A. and TATSUMI R.. "AIP Proceedings $N^{\circ} 50$ on laser interaction and laser processing materials research Society Meeting" (Ed. by FERRIS F.D., LEAMY M.J. and POATE J.M., Boston, 1979) p. 434.

12. FOGARASSY E., STUCK"E., GROB A. and SIFFERT P.. "Laser and electron beam processing of materials" (WHITE C.W. and PEERCY P.S. eds, Academic Press, New York, 1980) p. 117.

13. SMITH B.J. and STEPHEN J.. Rad. Eff. 14 (1974) 181.

14. HILL C.. "Laser Annealing of Semiconductor". (Ed. by POATE J.M. and MAYER J.W., Academic Press, New York, 1982) p. 511.

15. SAH C.T., NOYCE R.N. and SHOCKLEY W. P Proc. IRE 45 (1957) 1228.

16. HOVEL H.J.. "Semiconductors and Semimetals", Vol. 11, Sdar Celis (Ed. by WILLARDSON R.K. and BEER A.C., Academic Press, New York, 1975).

17. MERTENS R.P., VAN MEERBERGEN J.L., NIJS J.F. and VAN OVERSTRAETEN R.J., IEEE Trans. Electron. Devices, Vo1. Ed 27 (1980) 949.

18. BORDFFKA H., KRIMMEL E.F., LINDER M. and RUNGE H.. "Laser and Electron beam processing of electronic materials", Ref. 12, p. 178.

19. SLAOUI A.. Rapport de DEA "Etude du processus de recombinaison dans les cellules solaires monocristallines par les caractéristiques I-V d'obscurité", (Centre de Recherches Nucléaíres de STRASBOURG, 1982).

20. MILLER G.L., BENTON J.L., KIMERLING L.C., ROBINSON D.A.H. and RODGERS J.W.. Private Communication, Be11 Laboratories (1978). 